\title{
Prevalence of personality disorders in patients with fibromyalgia: a brief review
}

\author{
Luigi Attademo ${ }^{1}$ and Francesco Bernardini ${ }^{2}$ \\ ${ }^{1}$ USC Psychiatry 1, Department of Mental Health, Azienda Socio-Sanitaria Territoriale (ASST) "Papa Giovanni XXIII", \\ Bergamo, Italy \\ ${ }^{2}$ Department of Psychiatry, Erasme Hospital, Université Libre de Bruxelles (ULB), Anderlecht, Belgium
}

\begin{abstract}
Fibromyalgia (FM) is a complex musculoskeletal pain disorder characterized by widespread pain, fatigue, and other functional symptoms. Patients with FM are frequently affected by psychiatric disorders. Clinicians typically observe certain personality characteristics or traits associated with FM, but there is still a lack of studies about personality disorders (PDs) in patients with FM. Aim of our brief review is to summarize the literature to date on prevalence of PDs in FM. We searched the PubMed electronic database for all articles up to 1 February 2017, and identified a number of reports about prevalence of PDs in patients with FM. Most of studies show that the proportion of PDs diagnosed in patients with FM appears far greater than that found in the general population. We suggest that is very useful to evaluate PDs in patients with FM systematically, in order to improve the understanding, assessment, and treatment of this clinical condition.
\end{abstract}

Key words: brief review; fibromyalgia; personality disorders

Received 12 February 2017; revised 23 August 2017; accepted 23 November 2017; first published online 22 December 2017

\section{Introduction}

Fibromyalgia (FM) is a common and complex musculoskeletal pain disorder, characterized by long-lasting widespread pain and abnormal tenderness, associated with variable stiffness, fatigue, poor quality of sleep, cognitive disturbances, and psychological distress (Wolfe et al., 1990; Mease et al., 2009). A recent review by Queiroz (2013) found that the global mean prevalence of FM in the general population was $2.7 \%$, and that the mean rate was $3.1 \%$ in the Americas, $2.5 \%$ in Europe, and $1.7 \%$ in Asia. The 1990 diagnostic criteria proposed by the American College of Rheumatology estimate a female to male ratio of 7:1 (Clauw, 2014). The diagnostic criteria are still a matter of debate, and FM continues to be particularly difficult to diagnose and treat (Rose et al., 2009).

Correspondence to: Luigi Attademo. USC Psychiatry 1, Department of Mental Health, Azienda Socio-Sanitaria Territoriale (ASST) "Papa Giovanni XXIII", Piazza OMS 1, 24127 Bergamo, Italy. Email: luigi.attademo@hotmail.it

(C) Cambridge University Press 2017
Clinicians should be familiar with the signs and symptoms of FM and know that there are certain conditions associated with FM (Jahan et al., 2012). For example, a substantial lifetime psychiatric comorbidity in patients with FM has been found, suggesting that FM might share underlying pathophysiologic associations with some psychiatric disorders (Arnold et al., 2006). Psychological, behavioural, and social issues have been shown to affect the pathogenesis of FM and complicate its treatment (Fu et al., 2015). Comorbid psychiatric disorders include major depressive disorder, generalized anxiety disorder, obsessive-compulsive disorder, and post-traumatic stress disorder (Clauw, 2014). In our opinion, personality disorders (PDs) are frequently comorbid with FM too. But, although clinicians typically recognize certain personality characteristics or traits that can be associated with FM (Malin and Littlejohn, 2012), and patients with FM have been described as perfectionist (Herken et al., 2001), introspective, demanding (Amir et al., 2000), and occasionally exhausting to manage (Asbring and Närvänen, 2003), there is still a clear lack of studies about PDs in patients with FM. 
The aim of our review article is to narratively summarize the literature to date on PDs in FM and give recommendations for future research directions in order to better understand the role of PDs in the pathogenesis and impact of FM and to improve the management and treatment of this complex, highly impacting disorder. We think that PDs and FM are strictly associated with each other, and that this comorbidity has to be promptly identified during the consultation practice, in order to offer the patients a more holistic health care in this area.

\section{Methods}

We searched the PubMed electronic database for all articles up to 1 February 2017, and no initial date was used. Search terms included 'fibromyalgia' combined with 'axis II' or 'personality disorder' or 'personality disorders' or 'personality disordered'. The search included all languages. In total, 37 articles were identified. We selected seven original research reports related to the prevalence of PDs in patients with FM (Martinez et al., 1995; Thieme et al., 2004; Rose et al., 2009; Uguz et al., 2010; Garcia-Fontanals et al., 2014; Gumà-Uriel et al., 2016; Kayhan et al., 2016). We excluded 30 articles, on the basis of the following exclusion criteria: (a) studies unrelated to the topic and (b) letters or general comment papers not reporting research findings. Conference abstracts, doctoral dissertations, and grey literature were not eligible based on reporting PD prevalence. References lists were hand searched for missing papers, but hand searching identified no further reports. Three additional original research reports were included in this review instead, based on our knowledge of the subject (Cerón Muñoz et al., 2010; Pando Fernández, 2011; Fu et al., 2015).

\section{Results and discussion}

We identified 10 reports of prevalence of PDs in patients with FM (Martinez et al., 1995; Thieme et al., 2004; Rose et al., 2009; Cerón Muñoz et al., 2010; Uguz et al., 2010; Pando Fernández, 2011; Garcia-Fontanals et al., 2014; Fu et al., 2015; GumàUriel et al., 2016; Kayhan et al., 2016). Among them, six studies were performed in outpatient rheumatology settings (Martinez et al., 1995; Thieme et al., 2004; Uguz et al., 2010; Pando Fernández, 2011; Garcia-Fontanals et al., 2014; Fu et al., 2015), two studies in a primary health care setting (Cerón Muñoz et al., 2010; Gumà-Uriel et al., 2016), one study in an outpatient physical therapy service (Kayhan et al., 2016), and one study in a consultation-liaison psychiatry setting (Rose et al., 2009). Four articles focused on samples of only female patients with FM (Martinez et al., 1995; Thieme et al., 2004; Garcia-Fontanals et al., 2014; Kayhan et al., 2016). A categorical classification system was used for the diagnosis of PDs in eight studies (Thieme et al., 2004; Rose et al., 2009; Cerón Muñoz et al., 2010; Uguz et al., 2010; Pando Fernández, 2011; Fu et al., 2015; Gumà-Uriel et al., 2016; Kayhan et al., 2016). The most used PDs categorical assessment instrument was the Structured Clinical Interview for DSM-III-R (Spitzer et al., 1990) and for DSM-IV (First et al., 1996) $(n=4)$, followed by the ICD-10 International Personality Disorder Examination (Loranger, 1999) $(n=3)$. One study used the Personality Diagnostic Questionnaire-4 (Abdin et al., 2011). As for PDs dimensional assessment, one study used the Temperament and Character Inventory-Revised (Cloninger, 1999), and one study the Kurt Schneider's (1959) method for the diagnosis of PDs.

Table 1 summarizes the results from the 10 reviewed articles, in descending chronological order. Obsessive-compulsive PD was found to be the most common in three samples (Rose et al., 2009; Uguz et al., 2010; Pando Fernández, 2011), Avoidant PD was the most common in two samples (Fu et al., 2015; Gumà-Uriel et al., 2016), Histrionic PD was the most common in two samples (Cerón Muñoz et al., 2010; Kayhan et al., 2016), and Borderline PD was the most common in one sample (Thieme et al., 2004). Two studies did not report the prevalence of specific PDs (Martinez et al., 1995; Garcia-Fontanals et al., 2014). Most of studies highlight that the most prevalent PDs diagnosed in patients with FM are those belonging to Cluster C disorders (Rose et al., 2009; Uguz et al., 2010; Pando Fernández, 2011; Garcia-Fontanals et al., 2014; Fu et al., 2015; Gumà-Uriel et al., 2016) in the Diagnostic and Statistical Manual of Mental Disorders. Cluster C include three PDs sharing anxious and fearful features (avoidant, dependent, and obsessivecompulsive) (Sadock et al., 2014). 
Table 1 Main findings from studies of prevalence of personality disorders in patients with fibromyalgia

\begin{tabular}{|c|c|}
\hline Authors and year & Study characteristics \\
\hline $\begin{array}{c}\text { Kayhan et al. } \\
(2016)\end{array}$ & $\begin{array}{l}\text { A case-control study involved } 96 \text { female } \\
\text { FM patients admitted to the outpatient } \\
\text { Physical Therapy Unit of Mevlana } \\
\text { University School of Medicine, Turkey, } \\
\text { and } 94 \text { healthy women }\end{array}$ \\
\hline $\begin{array}{l}\text { Gumà-Uriel et al. } \\
(2016)\end{array}$ & $\begin{array}{l}\text { A cross-sectional study was performed } \\
\text { using the baseline data of } 216 \mathrm{FM} \\
\text { patients (aged 18-75 years) } \\
\text { participating in a randomized, } \\
\text { controlled trial carried out in three } \\
\text { primary health care centres situated } \\
\text { in Barcelona, Spain }\end{array}$ \\
\hline Fu et al. (2015) & $\begin{array}{l}\text { The study sample consisted of } 48 \text { FM } \\
\text { patients recruited by mailing, or } \\
\text { handing out surveys in an outpatient } \\
\text { rheumatology office in Syracuse, } \\
\text { NY, USA }\end{array}$ \\
\hline $\begin{array}{l}\text { Garcia-Fontanals } \\
\text { et al. (2014) }\end{array}$ & $\begin{array}{l}\text { From an initial sample of } 150 \text { FM patients } \\
\text { at the Rheumatology Department, } \\
\text { Hospital CIMA Sanitas, Barcelona, } \\
\text { Spain, the final sample consisted of } \\
42 \text { female FM patients (aged } 32-63 \text { yrs) } \\
\text { and } 38 \text { healthy controls }\end{array}$ \\
\hline $\begin{array}{l}\text { Pando Fernández } \\
\text { (2011) }\end{array}$ & $\begin{array}{l}\text { An observational, descriptive, cross- } \\
\text { sectional study involved } 30 \text { FM patients } \\
\text { (aged } 29-63 \text { years) selected by the } \\
\text { service of rheumatology of the Hospital } \\
\text { General of Ciudad Real, Spain }\end{array}$ \\
\hline
\end{tabular}

Uguz et al. (2010) The study included 128 consecutive FM patients who admitted to rheumatology outpatient clinic of a university hospital in Konya, Turkey. The final sample included $103 \mathrm{FM}$ patients and 83 control subjects

Cerón Muñoz et al. A cross-sectional descriptive study in an (2010) urban Primary Care centre in Barcelona, Spain, was performed selecting $132 \mathrm{FM}$ patients (aged $\geqslant 18$ years)

Rose et al. (2009) 30 FM outpatients were examined consecutively by the consultationliaison psychiatric service of the Centre Hospitalier Régional Universitaire and of the Saint-Philibert Hospital in Lille, France

Thieme et al. $\quad 115$ female FM patients (aged 21-68 (2004)

Martinez et al. (1995)

years) were recruited from rheumatologic outpatient departments as well as from a Hospital for Rheumatic Disorders at Berlin-Buch, Germany

47 female FM patients (aged 21-65 years) and 25 random selected control
Personality Diagnostic patients were studied at the General Medical and Rheumatology Out-patient Clinic of the Conjunto Hospitalar de Sorocaba, Brazil
Personality disorders

assessment instruments

Structured Clinical Interview for DSM-III-R Personality Disorders (SCID-II)

DSM-IV version of the International Personality Disorder Examination Screening Questionnaire (IPDE-SO) Questionnaire-4 (PDQ-4)

Temperament and Character Inventory-Revised (TCI-R)

ICD-10 International Personality

Disorder Examination (IPDE)

Structured Clinical Interview

for DSM-III-R Personality

Disorders (SCID-II)

Main findings

Of the 96 patients, $13(13.5 \%)$ had a PD.

The histrionic was the most common $(10.4 \%)$ and was the only PD significantly more prevalent in the patient group than in the control group Of the 216 participants in the study, 157 $(72.7 \%)$ completed the IPDE-SO and of these, $102(65.0 \%)$ had a possible PD. The most prevalent PDs in the sample were: avoidant $(41.4 \%)$, obsessivecompulsive $(33.1 \%)$, borderline $(27.0 \%)$, and schizoid $(15.3 \%)$

$27(56.3 \%)$ patients had a PD. Avoidant

$(27.1 \%)$ was the most common, followed by depressive $(25.0 \%)$, paranoid $(22.9 \%)$, and obsessivecompulsive $(20.8 \%)$

A total of $36.0 \%$ of FM patients presented a possible psychometric diagnosis of $\mathrm{PD}$, mainly from Cluster C $(26.0 \%$, $n=11)$, although there were no significant differences from the control group

28 (93.3\%) patients had a PD. Obsessivecompulsive (anankastic) (33.3\%) was the most common, followed by avoidant $(30.0 \%)$, schizoid $(13.3 \%)$, and dependent $(10.0 \%)$

Any PD (31.1\% versus $13.3 \%)$, obsessivecompulsive $(23.3 \%$ versus $3.6 \%)$, avoidant $(10.7 \%$ versus $2.4 \%)$, and passive-aggressive (10.7\% versus $2.4 \%$ ) PDs were significantly more common in the patient group compared to the control group

ICD-10 International Personality Disorder Examination (IPDE)

Of the 132 participants in the study, 121 $(91.7 \%)$ completed the IPDE that was positive in $96.7 \%$ of the sample. The more frequent PDs were: histrionic (71.9\%), obsessive-compulsive (71.1\%), borderline (emotionally unstable) $(66.1 \%)$, and avoidant $(61.9 \%)$

Structured Clinical Interview for $46.7 \%$ received at least one diagnosis of DSM-IV Personality Disorders (SCID-II)

$\mathrm{PD}$, including obsessive-compulsive $(30.0 \%)$, borderline $(16.7 \%)$, depressive $(16.7 \%)$, and avoidant $(13.3 \%)$

Structured Clinical Interview for DSM-IV Personality Disorders (SCID-II)

PDs were found to be present in $8.7 \%$ of patients, $5.25 \%$ borderline, and $1.75 \%$ revealing either an avoidant or dependent PD

Schneider's method for the diagnosis of personality disorders
$63.8 \%$ of the FM patients and $8.0 \%$ of the control group had a PD, respectively, and the comparison was statistically significant 
Studies conducted on large representative samples of community populations found prevalences of PDs between 13.4 and 14.8\% (Torgersen et al., 2001; Grant et al., 2004); a more recent review by Samuels (2011) found that the prevalence of PDs in the general population was between 6 and $13 \%$. Differently, our review shows that the prevalence of PDs in patients with FM ranged from 8.7 to $96.7 \%$, so we can say that the proportion of PDs diagnosed in patients with FM appears far greater than that found in the general population. For example, in our review, the largest sample study included the data from 157 patients with FM participating in a randomized, controlled trial, and showed that $65.0 \%$ of the sample had a possible PD (Gumà-Uriel et al., 2016).

PDs appear to be frequent comorbid disorders in patients with FM. Moreover, it has been demonstrated that patients with FM and comorbid-PD have worse functional status and higher direct costs, especially in terms of visits to primary health care and specialists (Gumà-Uriel et al., 2016). Reviewed studies underline a possible link between FM and PDs, but this link has to be further investigated along with neurobiological research to better understand the FM etiopathogenetic mechanisms. What we know so far about FM is that genetics plays a role in the development of the FM as well as in the serotonin and noradrenaline system (Bazzichi et al., 2016). Other neuroendocrine transmitters such as substance $\mathrm{P}$, growth hormone, and cortisol seem to be involved too. Sleep alterations, aberrant pain processing, and a disturbed stress-adaptation response are often found in patients with FM. This all suggests a possible major role for autonomic and neurotransmitters abnormalities and for stress response alterations (Jahan et al., 2012). These pathophysiological mechanisms could be shared with PDs, at least in part.

Several limitations deserve mention in this discussion. Surely, a major limitation of this paper is the decision to perform only a narrative review; the total prevalence of PDs was not pooled together where possible, providing $95 \% \mathrm{CI}$ and heterogeneity estimates, and the estimated pooled prevalence of specific PDs was not performed to gauge the most common subtype of PD in FM. Another limitation is that some of the reviewed studies used noncategorical assessment methods to determine PDs; specifically, two studies were included who utilized the Temperament and Character Inventory-Revised
(Garcia-Fontanals et al., 2014) and Schneider's method (Martinez et al., 1995) for the diagnosis of PDs. A third limitation lies in the fact that only PubMed electronic database was used for searching, suggesting the possibility of some missing papers.

However, despite the limitations, we believe that this narrative review could add useful information to the literature and the journals readership including practicing clinicians. Prompt diagnosis and treatment of FM and of associated conditions may produce substantial improvement in quality of life of affected patients. Due to the high frequency of the association between FM and psychiatric disorders in general, a careful clinical assessment is warranted to identify FM patients who may also benefit from specific psychotropic medications, and from psychotherapeutic and psychosocial interventions. We suggest that it is very useful to systematically evaluate PDs too in patients with FM, in order to improve the understanding, assessment, and treatment of this complex clinical condition. Knowledge of the core features of PDs may help physicians to recognize, diagnose, and treat affected patients, for example suggesting a specialist's consultation. Furthermore, we suggest that PDs should be evaluated using validated assessment instruments and not only on the basis of clinician's judgment, in order to provide a reliable diagnosis. As the symptoms of FM are related to stresses, an optimal treatment needs to be an ongoing process and has to be based on a patient centered approach (Jahan et al., 2012). Patients should participate in developing a care plan, this will help them to focus on positive lifestyle changes limiting anxiety and stress. Therefore, a close multimodal collaboration among general practitioners and specialists from different fields is essential for successful management of patients with FM.

\section{Acknowledgements}

None.

\section{Financial Support}

This research received no specific grant from any funding agency, commercial or not-for-profit sectors.

\section{Conflicts of Interest}

None. 


\section{References}

Abdin, E., Koh, K.G., Subramaniam, M., Guo, M.E., Leo, T., Teo, C., Tan, E.E. and Chong, S.A. 2011: Validity of the Personality diagnostic Questionnaire-4 (PdQ-4+) among mentally ill Prison inmates in Singapore. Journal of Personality Disorders 25, 834-41.

Amir, M., Neumann, L., Bor, O., Shir, Y., Rubinow, A. and Buskila, D. 2000: Coping styles, anger, social support, and suicide risk of women with fibromyalgia syndrome. Journal of Musculoskeletal Pain 8, 7-20.

Arnold, L.M., Hudson, J.I., Keck, P.E., Auchenbach, M.B., Javaras, K.N. and Hess, E.V. 2006: Comorbidity of fibromyalgia and psychiatric disorders. Journal of Clinical Psychiatry 67, 1219-225.

Asbring, P. and Närvänen, A.L. 2003: Ideal versus reality: physicians perspectives on patients with chronic fatigue syndrome (CFS) and fibromyalgia. Social Science \& Medicine 57, 711-20.

Bazzichi, L., Giacomelli, C., Consensi, A., Atzeni, F., Batticciotto, A., Di Franco, M., Casale, R. and Sarzi-Puttini, P. 2016: One year in review 2016: fibromyalgia. Clinical and Experimental Rheumatology 34 (Suppl 96), S145-149.

Cerón Muñoz, A.M., Centelles Mañosa, F., Abellana Senglà, M. and Garcia Capel, S. 2010: [Fibromyalgia and personality disorders]. Semergen - Medicina de Familia. 36, 501-6.

Clauw, D.J. 2014: Fibromyalgia: a clinical review. JAMA 311, $1547-555$.

Cloninger, C.R. 1999. The temperament and character inventory-revised. St Louis, MO: Center for Psychobiology of Personality, Washington University.

First, M.B., Spitzer, R.L., Gibbon, M. and Williams, J.B.W. 1996. User's guide for the structured clinical interview for DSM-IV personality disorders (SCID-II). Washington, DC: American Psychiatric Association, 1-80.

Fu, T., Gamble, H., Siddiqui, U. and Schwartz, T. 2015: Psychiatric and personality disorder survey of patients with fibromyalgia. Annals of Depression and Anxiety 2, 1064.

Garcia-Fontanals, A., García-Blanco, S., Portell, M., Pujol, J., Poca-Dias, V., García-Fructuoso, F., López-Ruiz, M., Gutiérrez-Rosado, T., Gomà-i-Freixanet, M. and Deus, J. 2014: Cloninger's psychobiological model of personality and psychological distress in fibromyalgia. International Journal of Rheumatic Diseases 19, 852-63.

Grant, B.F., Hasin, D.S., Stinson, F.S., Dawson, D.A., Chou, S.P., Ruan, W.J. and Pickering, R.P. 2004: Prevalence, correlates, and disability of personality disorders in the United States: results from the national epidemiologic survey on alcohol and related conditions. Journal of Clinical Psychiatry 65, 948-58.

Gumà-Uriel, L., Peñarrubia-María, M.T., Cerdà-Lafont, M., Cunillera-Puertolas, O., Almeda-Ortega, J., FernándezVergel, R., García-Campayo, J. and Luciano, J.V. 2016: Impact of IPDE-SQ personality disorders on the healthcare and societal costs of fibromyalgia patients: a crosssectional study. BMC Family Practice 17, 61.
Herken, H., Gürsoy, S., Yetkin, O.E., Virit, O. and Esgi, K. 2001: Personality characteristics and depression level of the female patients with fibromyalgia syndrome. International Medical Journal 8, 41-44.

Jahan, F., Nanji, K., Qidwai, W. and Qasim, R. 2012: Fibromyalgia syndrome: an overview of pathophysiology, diagnosis and management. Oman Medical Journal 27, 192-195.

Kayhan, F., Küçïk, A., Satan, Y., İgün, E., Arslan, Ş. and Ilik, F. 2016: Sexual dysfunction, mood, anxiety, and personality disorders in female patients with fibromyalgia. Neuropsychiatric Disease and Treatment 12, 349-55.

Loranger, A.W. 1999: International Personality Disorder Examination: IPDE; DSM-IV and ICD-10; Interviews. PAR. Odessa, FL.

Malin, K. and Littlejohn, G.O. 2012: Personality and fibromyalgia syndrome. The Open Rheumatology Journal 6, 273-285.

Martinez, J.E., Ferraz, M.B., Fontana, A.M. and Atra, E. 1995: Psychological aspects of Brazilian women with fibromyalgia. Journal of Psychosomatic Research 39, 167-74.

Mease, P., Arnold, L.M., Choy, E.H., Clauw, D.J., Crofford, L.J., Glass, J.M., Martin, S.A., Morea, J., Simon, L., Strand, C.V. and Williams, D.A., OMERACT Fibromyalgia Working Group 2009: Fibromyalgia syndrome module at OMERACT 9: domain construct. The Journal of Rheumatology 36, 2318-2329.

Pando Fernández, M.P. 2011: [Fibromyalgia and psychotherapy]. Revista Digital de Medicina Psicosomática y Psicoterapia 1, 1-42.

Queiroz, L.P. 2013: Worldwide epidemiology of fibromyalgia. Current Pain and Headache Reports 17, 356.

Rose, S., Cottencin, O., Chouraki, V., Wattier, J.M., Houvenagel, E., Vallet, B. and Goudemand, M. 2009: [Study on personality and psychiatric disorder in fibromyalgia]. Presse Medicale. 38, 695-700.

Sadock, B.J., Sadock, V.A. and Ruiz, P. 2014. Kaplan \& Sadock's synopsis of psychiatry: behavioral sciences/clinical psychiatry, 11th edition. Philadelphia: LWW.

Samuels, J. 2011: Personality disorders: epidemiology and public health issues. International Review of Psychiatry 23, 223-33.

Schneider, K. 1959: Clinical psychopathology. Grune \& Stratton. New York, NY.

Spitzer, R.L., Williams, J.B.W., Gibbon, M. and First, M. 1990. Manual for the structured clinical interview for DSM-III-R personality disorders. Washington, DC: American Psychiatric Press, 7.

Thieme, K., Turk, D.C. and Flor, H. 2004: Comorbid depression and anxiety in fibromyalgia syndrome: relationship to somatic and psychosocial variables. Psychosomatic Medicine. 66, 837-44.

Torgersen, S., Kringlen, E. and Cramer, V. 2001: The prevalence of personality disorders in a community sample. Archives of General Psychiatry 58, 590-96. 
Uguz, F., Ciçek, E., Salli, A., Karahan, A.Y., Albayrak, I., Kaya, N. and Ŭgurlu, H. 2010: Axis I and Axis II psychiatric disorders in patients with fibromyalgia. General Hospital Psychiatry 32, 105-7.

Wolfe, F., Smythe, H.A., Yunus, M.B., Bennett, R.M., Bombardier, C., Goldenberg, D.L., Tugwell, P., Campbell, S.M., Abeles, M., Clark, P., Fam, A.G.,
Farber, S.J., Flechtner, J.J., Franklin, C.M., Gatter, R.A., Hamaty, D., Lessard, J., Lichtbroun, A.S., Masi, A.T., McCain, G.A., Reynolds, W.J., Romano, T.J., Russell, I.J. and Sheon, R.P. 1990: The American College of Rheumatology 1990 criteria for the classification of fibromyalgia. Report of the Multicenter Criteria Committee. Arthritis and Rheumatism 33, 160-72. 